\title{
LA NOVELA CUBANA CONTEMPORANEA: ALTERNATIVAS Y DESLINDES
}

\author{
POR \\ ROGELIO RODRIGUEZ CORONEL \\ UNEAC
}

Es ya un lugar común en los estudios teóricos sobre la novela latinoamericana el reconocimiemto del carácter predominantemente social de sus proyecciones. De hecho, esta dimensión ha sido uno de los elementos más explorados, sobre todo por aquellos críticos e investigadores que conciben el análisis del texto literario a partir de sus aristas gnoseológicas y valorativas en confrontación con una realidad que, por sus urgencias, reclama una atención prioritaria. Sin embargo, el enfoque — válido en síha generado una suerte de espejismo teórico en el que se plantean como términos excluyentes lo social y lo experimental, el «realismo» y la activación de las formas, la reproducción de la realidad y la reflexión sobre lá misma.

En principio, la vocación social de la novela cubana resulta una verdad necesaria, pero en ningún caso suficiente para explicar las peculiaridades que asume el proceso literario. Su validación no puede fundamentarse únicamente desde esta óptica, que, por otra parte, no marcaría diferencias sustanciales con respecto a la novelística de otros países y otras épocas. En todo caso, se apelaría a un rasgo presente en el género desde su génesis. Y algo más: no es menester que una obrá literaria explicite una problemática social para que cumpla una función «referencials. En términos generales, el grado de complejidad en la elaboración formal no supone necesariamente el abandono o minimización de las propiedades comunicativas.

Un análisis de la experiencia narrativa de las últimas décadas revela que la evolución de la novela cubana y continental en nuestro siglo ha entrañado una búsqueda definidora: el hallazgo de un discurso que promueva la confrontación de lo americano y lo universal, el reconocimiento del paisaje y la integración de lenguajes, la pesquisa ontológica proyectada en 
una nueva dimensión, la diversificación de las vías y modos expresivos. En lo que respecta a la crítica, estas modelaciones obligan a un replanteo del instrumental analítico. Alternativas y deslindes reclaman atención prioritaria.

La asimilación y cambio de funciones de elementos provénientes de métodos artísticos hegemónicos en centros difusores de cultura foráneos, le ha otorgado un rango de libertad a la novela latinoamericana que explica su proyección estética contemporánea, su activa modernidad. Es la consecuencia de una integración inherente al discurso narrativo americano desde sus inicios, dictado por las disimilitudes existentes entre las modelaciones literarias de realidades distintas, pero dependientes; de necesidades expresivas diferentes, pero interactuantes. En el espacio cultural de América Latina no sólo se difuminan los límites de las propuestas estéticas de corrientes y escuelas europeas y norteamericanas, sino también surgen paradigmas propios y alcanza registros particulares el diálogo que sostiene el texto con su interlocutor, su incidencia en el mundo de relaciones sociopolíticas y culturales que lo genera y acoge.

Desde el siglo XIX, la novela cubana, atenta a orientaciones literarias de la época, cumple con una función analítico-social. Las obras de Anselmo Suárez y Romero, Cirilo Villaverde y Ramón Meza profundizan sucesivamente en los estratos conformadores de la sociedad colonial. A la visión romántica de Francisco, propia del abolicionismo reformista de las primeras décadas, sucede la reconstrucción - no exenta de imprecisiones, pero valiosa en su conjunto- del universo de relaciones del sistema colonial en Cecilia Valdés. El esquema romántico-heroico vertebra, a veces débilmente, un mundo de valores que intenta la reproducción, el lienzo de época, el trazado de figuras y contradicciones del contexto. En este caso, la expresión costumbrista funciona a favor de la revelación de coordenadas esenciales. Pero no será hasta Mi tío el empleado, de Meza, cuando se manifieste, desde una perspectiva renovadora, el carácter profundamente deformador de las estructuras de la colonia. Sin perder una vocación de análisis social, el contenido «realista» en la obra de Meza asume otras proyecciones. La caricatura, el humor, lo grotesco de los personajes, el sentido expresionista de la imagen, diferencia la novela de sus precedentes.

Pudiera pensarse en esta dirección que la narrativa de las primeras décadas republicanas continuaría de manera definida el proceso de maduración del género. Teniendo en cuenta la tradición, sería el instrumento idóneo para indagar y expresar las circunstancias socioeconómicas y políticas de un país cuya identidad e independencia han sido secuestradas por la intervención norteamericana. Ciertamente, en los primeros años republicanos crece el número de obras publicadas. La reflexión en torno a las 
vicisitudes sociales denota una preocupación creciente por la situación y el destino de Cuba, y en medio del desconcierto, la frustración o el pesimismo que dominan una zona considerable del pensamiento de la época, se elevan las «rebeldías solitarias», la palabra que enjuicia y la búsqueda de respuestas o soluciones esclarecedoras. La conjura (1909), de Jesús Castellanos, y en mayor medida Las honradas (1918) y Las impuras (1919), de Miguel de Carrión, son resultado de un esfuerzo interpretativo que testimonia un estado de conciencia. Pero el discurso narrativo sigue enfrascado en la asimilación y adecuación de corrientes estilísticas del siglo anterior. El realismo y el naturalismo franceses orientan la disección de la realidad. Una conciencia «dócil» (o subordinada) en términos de invención literaria, denota un fenómeno complejo: la ausencia de una perspectiva eficazmente «libre» para juzgar y expresar las determinaciones de la etapa.

El análisis superfluo de la novelística de estos años se ha limitado a subrayar las «influencias», detectar carencias y aspectos más o menos evidentes; pero ha dejado intacto lo de mayor importancia: la relación que existe entre las limitaciones de perspectiva frente a la realidad (el proceso de penetración imperialista, las deformaciones estructurales y superestructurales de la nación) y la ausencia de nuevos métodos narrativos capaces de captar las peculiaridades de una experiencia histórica.

De hecho, la adopción - aun con variantes- de modelos composicionales hegemónicos revela el signo de la época: el cambio en el sistema de dominación (colonialismo español - imperialismo norteamericano) y sus relaciones inherentes, impone la «ilusión» de una modernidad actuante, pero no modifica raigalmente las interacciones que nutren la experiencia literaria. En el caso de Castellanos, y con mayor énfasis en Carrión, asumir el punto de vista de una burguesía liberal no constituye, en esencia, un factor de «ruptura». Entre una oligarquía vinculada al capital monopolista norteamericano y las clases explotadas y sectores marginados, el novelista tensa su sensibilidad para enjuiciar éticamente los conflictos de la nación; pero el impulso analítico se «mediatiza» por las subordinaciones impuestas.

Con mayor agilidad, el ex ferroviario Carlos Loveira traza en Generales $y$ doctores (1920) y Juan Criollo (1928) la caracterización del proceso. Una visión más dinámica (en alguna medida más «libre») de la estructura clasista cubana permite la configuración de un panorama epocal. Juan Criollo resume una experiencia: el «pícaro» reaparece asimilado al contexto.

Prosiguiendo la actitud narrativa anterior, José Antonio Ramos en Coaybay (1927) y Luis Felipe Rodríguez en La conjura de la ciénaga (1924), reescrita y publicada bajo el título de Ciénaga en 1937, pretenden 
ofrecer una metaforización de la Cuba neocolonizada. En ellas se perfila el propósito de una interpretación «totalizadora» de la realidad.

Pero el gesto de renovación del discurso narrativo comienza a percibirse desde los años treinta con la aparición de un conjunto de obras significativas. El laberinto de sí mismo (1931) y Cresival (1936), de Enrique Labrador Ruiz; ;Ecue-Yamba-O! (1933), de Alejo Carpentier; Pedro Blanco, el negrero (1933), de Lino Novás Calvo; Hombres sin mujer (1938), de Carlos Montenegro; Contrabando (1938), de Enrique Serpa, y el grupo que forman Presidio modelo (esc. 1933), Realengo 18 (esc. 1934) y Aventuras del soldado desconocido (inconclusa), de Pablo de la Torriente Brau, señalan una etapa de transición hacia un modo narrativo que recibe las incitaciones vanguardistas ya presentes en la poesía de la década anterior, y que se corresponde con las expectativas renovadoras que despierta la lucha contra la dictadura de Gerardo Machado, la llamada Revolución del Treinta. En todos los casos, la búsqueda de identidad, el rescate de valores nacionales y el descubrimiento de aristas socioculturales que posibiliten un nuevo cauce a la formulación artístico-literaria, identifican un proyecto renovador, la apertura a concepciones estéticas que legalizan una propuesta de vanguardia.

Desde el punto de vista analítico, la pluralidad de expresiones, líneas y tendencias, no niega, sino reafirma, el carácter integral de la experiencia vanguardista. Se trata de un momento inicial, de tanteos y proposiciones que abarcan desde la exploración del ámbito afrocubano en la obra de Carpentier, la experimentación del lenguaje para la reconstrucción de una figura histórica en Novás Calvo o las novelas «gaseiformes» de Labrador Ruiz, hasta la vocación «realista» de Serpa y el compromiso militante de Pablo de la Torriente Brau con las urgencias de la lucha revolucionaria. El carácter testimonial de la obra de este último, unido a su funcionalidad estética, anticipa el desarrollo que alcanzará posteriormente esta modalidad.

La apertura a nuevas experiencias con el lenguaje y las estructuras narrativas se extiende a la década del cuarenta. Labrador publica Anteo (novela gaseiforme) (1940), Carne de quimera (1947) y La sangre hambrienta (1950); Alejo Carpentier, luego de su aventura surrealista en Francia y de recorrer tierras americanas, escribe El reino de este mundo (1949); mientras que José Lezama Lima inicia la gestación de su monumental Paradiso (1966). No obstante, el proyecto vanguardista no cristaliza definitivamente hasta dos décadas después.

Por razones varias, algunas biográficas y otras sociológicas, aquellos novelistas que ofrecen signos de modernidad en los treinta, con la excepción de Labrador Ruiz y Carpentier, no continúan sus búsquedas dentro del 
género. Lino Novás Calvo deriva hacia la cuentística definitivamente para convertirse en uno de sus más notables renovadores; Pablo de la Torriente Brau muere en las barricadas republicanas españolas; Carlos Montenegro añade a su obra otro libro de cuentos; Enrique Serpa solamente publica La trampa (1956), en Buenos Aires, y no supera a la anterior.

Habría que interrogarse si el proceso creciente de desintegración y deformación de los valores nacionales durante la década del cincuenta, la crisis de conciencia y el grado de agresividad que adquiere la experiencia social en estos años no son factores que inciden en la perspectiva y la sensibilidad de los creadores y obstaculizan que se consolide un discurso cuyos rasgos predominantes se refieren al rastreo de las peculiaridades ontológicas de nuestro entorno y del hombre que lo habita. Es decir, en qué medida factores contextuales explican la discontinuidad de un discurso. que pretende el apresamiento (ya no simplemente reproductor) de valores esenciales. De hecho, el vacío cultural de estos años y la traumática existencia cotidiana reprimen la manifestación de este proceso. Muchos de los mejores escritores emigran y dan a conocer sus obras en el extranjero. Alejo Carpentier publica Los pasos perdidos (1953) en México y El acoso (1956) en Buenos Aires. Virgilio Piñera, quien había traído a la poesía y al teatro cubanos un aliento de modernidad durante los años cuarenta, publica también en Buenos Aires su primera novela, La carne de René (1952); la segunda, Pequeñas maniobras, se escribe en 1956, también en A1 gentina, pero se publica en Cuba siete años más tarde, después del triunfo revolucionario, período en que se da a conocer su última novela, Presione, y diamantes (1967). En la Isla, el grupo Orígenes y la revista del mismo nombre intentan el rescate de la tradición, una «teleología» que asume el signo de «resistencia» frente al proceso de desintegración.

En este sentido, la aparición de El Siglo de las Luces (1962), de Alejo Carpentier, y de Paradiso (1966), de José Lezama Lima, publicadas después después del cambio social iniciado en 1959, aunque concebidas en el contexto descrito, legitiman la trayectoria del proyecto de vanguardia. Por vías distintas, ambas obras constituyen alternativas definidas frente a las demandas de una pseudocultura «oficial», resistentes a la crisis de identidad sufrida por la nación. Representan conceptual y artísticamente el grado más alto de realización del proyecto renovador, que ofrece sus primeros indicios en los años treinta.

En conjunto, la renovación del modo narrativo denota que se ha producido en la literatura cubana un cambio de sensibilidad y actitud para la captación de la realidad social. Esta nueva postura, que niega dialécticamente la óptica de promociones anteriores, valora la experimentación for- 
mal como la búsqueda de un código competente para expresar, con toda la complejidad y riquezas necesarias, la fisonomía material y espiritual del país o el continente.

Alejo Carpentier, que regresa a América Latina con la «capacidad de entendimiento» otorgada por el surrealismo francés, pero en contradicción con su retórica, inaugura una nueva visión del espacio, la historia y el hombre americanos al descubrir aquellos elementos esenciales que les proporcionan un perfil distintivo y los relaciona, a la vez, con un ámbito universal.

La poética de lo real-maravilloso y la práctica artística que la sustenta develan facetas de identidad ajenas al folclorismo y «tipicismos» de la novela regionalista precedente y proponen la articulación de un discurso de significado distinto: el barroco, homólogo de la propia realidad.

En otra dimensión, la propuesta estética de Lezama Lima, también barroca, funda una mirada inédita de lo cubano. Paradiso y Oppiano Licario (1977), inconclusa al morir el autor, trazan la imagen de un proceso histórico-cultural cuyas claves interpretativas se encuentran en el trasfondo del dibujo de las costumbres, la fijación del paisaje o la peripecia de los personajes. Es la concreción de una poética que comienza a fraguarse en los años cuarenta como respuesta a las circunstancias de un país «frustrado en lo esencial político». Si la desintegración nacional era el signo de la época, el fundador de Orígenes (1944-1956) va al rescate de esa identidad a través de la poesía, de la imagen artística que brinde una lectura trascendente del entorno, que corporice las dimensiones psicosociales y culturales de la nacionalidad estableciendo un entramado de relaciones implícitas con el espacio caribeño y universal.

Significativamente, tanto la novelística de Carpentier como la de Lezama funcionarán como modelos ideoestéticos para la obra de nuevas promociones de escritores. Estas asimilarán las propuestas de acuerdo con sus necesidades expresivas en el contexto revolucionario.

El cambio social, que se inicia en 1959, abre otras expectativas a la evolución de la literatura cubana. El proyecto renovador implica la transformación de la realidad socioeconómica, política y ética del país; trae consigo la recuperación de la identidad escamoteada. De inmediato se establecen las condiciones materiales y el apoyo moral para la reactivación de la práctica literaria y artística, a pesar de la penuria legada por la dictadura de Fulgencio Batista y las propias contradicciones que surgen en la definición del modelo de desarrollo revolucionario. Entre 1959 y 1965 se publican treinta y siete novelas de autores nacionales, hecho sin precedente en el campo editorial cubano. Desde entonces hasta hoy, alrededor de trescientas. Algunas fueron escritas antes del cambio social, pero 
la gran mayoría construye su mundo novelesco estimulados por las modificaciones que se operan en el ámbito social e individual.

Desde los primeros años de la década del sesenta, el discurso narrativo afronta el desafío estético resultante de la tensión que se establece entre una perspectiva renovadora, abierta al devenir, y la adopción de formas que garanticen la eficacia comunicativa de su lenguaje. La tradición literaria -nacional y universal - y la realidad contextual inmediata interactúan creando un substrato referencial que exprese la multiplicidad de puntos de vista y modos narrativos.

Entre 1960 y 1965 se publican obras tan disímiles en sus proyecciones como Bertillón 166 (1960) y El derrumbe (1964), de José Soler Puig; Gestos (1963), de Severo Sarduy; No hay problema (1961), El cataclismo (1965) y Memorias del subdesarrollo (1965), de Edmundo Desnoes; La situación (1963), de Lisandro Otero, y Tres tristes tigres (1964), de GuiIlermo Cabrera Infante, por citar ejemplos elocuentes. Quizá ello explique que la crítica y los estudios sobre la novela cubana de la época hayan insistido en establecer una dicotomía entre la llamada línea «realista» - «reflejo» de la realidad (Soler, Desnoes, Otero) — y la vertiente «experimental» (Sarduy, Cabrera Infante). En sentido general, a la primera se le atribuye un carácter social, histórico, cuyo objetivo primero será el significado, el «mensaje», en tanto que la segunda podría verse como un juego del significante con proyecciones que trascienden lo circunstancial.

Si bien esta suerte de tipología tiene su base en el análisis empírico de los rasgos dominantes en los textos, habría que precisar algunos conceptos. En principio, un lenguaje «realista» (aquí el término apunta al carácter reproductor que pueda ofrecer del referente) no puede identificarse, sin otras consideraciones, con una postura «comprometida» desde el punto de vista ideológico y político, como tampoco la experimentación con la palabra y las estructuras narrativas conducen en todos los casos a caminos de «evasión». Por el contrario, se sabe que las incitaciones de la realidad llevan generalmente, más tarde o más temprano, a un replanteo formal, a la activación o desautomatización de un discurso que le otorgó una dimensión estética a los significados del contexto anterior. Por supuesto, no se trata de un proceso rectilíneo ni inmediato. Todo lo contrario: está lleno de asechanzas, retrocesos y contradicciones de donde emergen los nuevos signos.

Por otro lado, el cambio social y sus repercusiones en la esfera literaria no se revelan obligatoriamente en la asunción de una temática social e histórica. Más allá, la revolución trae como consecuencia una readecuación (apertura, objetivación, enriquecimiento) desde la cual el novelista evalúa el pasado, la tradición, el legado cultural, el entorno, los valores en juego 
y la práctica artística. Por último, es necesario reflexionar sobre la significación histórico-literaria que portan actitudes contrastantes, e incluso divergentes, pero que remiten a una misma problemática sociocultural e ideoestética.

Vale observar que el empeño reproductor, testimonial, que preside una zona de la novelística cubana (bien sea de acontecimientos sociales, como en Soler, o de coyunturas existenciales, como en Desnoes y Otero) no se produce al margen de la asimilación de la experiencia vanguardista precedente. En estas obras se debate una problemática más compleja: el cambio de las funciones del significante en virtud de la jerarquización de significados éticos y políticos, sociales e históricos que sensibilizan la conciencia del escritor y establecen el área de una indagación que sitúa la realidad en un primer plano de análisis.

Las propuestas de Sarduy y de Cabrera Infante tienen otro sentido. La poética «neobarroca» del autor de Gestos, sobre todo en De donde son los cantantes (1967), prosigue la indagación ontológica sobre lo cubano que obsesionaba a Lezama, pero con una proyección diferente. Si las búsquedas que culminan en Paradiso procuraban devolverle un rostro al país, recobrar los valores primigenios de la nacionalidad a trávés de la literatura, como un resguardo ante la desintegración y enajenación de las décadas del cuarenta y el cincuenta, las obras de Sarduy refractan - al nivel de la estructura formal y la función del lenguaje - el caos y la deformación que supone la pérdida de identidad. La caricatura, el juego paródico adquieren primer plano. El discurso «desarticula» y promueve una lectura distanciada del contexto. Desasido de un ámbito que comienza a reintegrarse desde el punto de vista social y moral, además de político, desprovisto de una perspectiva que enjuicie críticamente el proceso nacional y anide nuevas expectativas, el mundo novelesco apela a arquetipos étnico-culturales, a una dimensión mítico-simbólica que fija su textura a través de las capacidades lúdicas y connotativas del lenguaje, estimulado por los postulados de Tel Quel y del nouveau roman francés.

La propuesta de Cabrera Infante sigue una orientación similar. Si Tres tristes tigres (1964) significa el intento de apresar un mundo cuya crisis de valores (sociales, culturales) sustenta la adopción de recursos narrativos propios a ese fin, La Habana para un infante difunto (1979), quince años después, revela, por una parte, la maduración de un lenguaje evocativo que traza, de manera distante, la imagen de una ciudad retenida en la memoria; por otra, la pérdida de un sentido vital, histórico, raigalmente vivo. La «maquetilla» sustituye — hábilmente construida - la expresión de contradicciones reales, actuantes, que nutren la renovación de una práctica artística. 
Curiosamente, después de los primeros años de la década del sesenta, la novela, menos urgida por testimoniar lo inmediato, va en busca de zonas más ocultas de la realidad, indaga en la conciencia y la psicología sociales del cubano a través de su universo mítico-cultural. Para ello libera al discurso de un carácter reproductor y se intensifican las apetencias experimentales con el lenguaje y las estructuras narrativas, en fructífero intercambio con la novelística continental. Es una voluntad de formas que se manifiesta, incluso, en obras ajenas a temáticas dominantes, como en Pasión de Urbino (1966), de Lisandro Otero, o Pailock, el prestidigitador (1966), de Ezequiel Vieta, primera parte de un proyecto ideoestético de amplias proporciones aún por concluir. Las búsquedas de estos años son plurales. Ezequiel Vieta, con Vivir en Candonga (1966), explora la ruptura de los parámetros genéricos a partir de la inclusión de procedimientos que provienen de otras formas discursivas con el propósito de renovar el tratamiento de una temática subrayada por el cambio social: las determinaciones existentes en los nexos que se tienden entre el individuo, sobre todo el intelectual, y la realidad histórica. A diferencia de otros textos de asunto similar, lo documental deja paso a una más intensa experimentación de estructura y lenguaje que se revierte en la consecución de un plano semántico más complejo.

Reynaldo González, por su parte, en Siempre la muerte, su paso breve (1968) apela al entramado intertextual de manifestaciones diversas de la cultura para ofrecer una imagen de lo cubano basada en la funcional asimilación de los espacios abiertos y los recursos movilizados por la nueva novela latinoamericana. Esta obra ensancha los inicios de la lucha revolucionaria al incluir las frustraciones y anhelos de la época asumidos desde un punto de vista psicosocial; con este fin, potencia el habla popular, previa selección e intensificación de expresiones idiomáticas, sentencias y modos de construcción, y revela mitos y creencias, actitudes y conductas que conforman un ámbito ajeno a todo localismo. De hecho, desaparece toda intención documentalista y se procura la creación de un mundo autosuficiente en sus dimensiones socioculturales, más allá de las referencias a las circunstancias históricas concretas.

La revelación del substrato mítico presente en la psicología social, la evocación poético-alegórica y el libre juego de estructuras y lenguaje alcanzan un momento culminante en Los niños se despiden (1968), de Pablo Armando Fernández, uno de los poetas mayores de la llamada «Generación del 50».

A través de la poesía filtra elementos significativos de la realidad y dibuja el perfil histórico-cultural del país. En verdad, el texto resulta un extenso poema donde se funden distintas formas literarias bajo el hálito 
de la magia poética. Lo propiamente novelesco está configurado por un tejido de rememoraciones que difuminan lo histórico-concreto dentro de una conciencia sumamente sensible, nutrida por mitos y creencias que provienen de la tradición familiar y comunitaria; esta conciencia protagonista tamiza el quehacer de todo un pueblo o las contingencias de la vida cotidiana y así adquieren, gracias a la tensión lírica que se genera, una íntima resonancia, pero sin perder su vastedad referencial. La historia, convertida en recuerdo, ensoñación o profecía, es la sustancia que dignifica al hombre y su existencia, lo que le proporciona un sentido.

Por otra parte, la aparición de Los niños se despiden indica que se han retomado las pautas de continuidad con respecto a la actitud estética de los escritores del grupo de Orígenes, en particular con la obra de Lezama Lima, pero con una perspectiva distinta que proviene del horizonte propuesto por la revolución. Desde este punto de vista, la tentación ontológica y la mitificación de lo cubano se transforma en una recuperación de la identidad histórica y una proyección hacia el futuro.

En suma, estas obras y otras sobresalientes del momento, como $\mathrm{La}$ vida en dos (1967), de Luis Agüero, o Celestino antes del alba (1967) y El mundo alucinante (1969), de Reinaldo Arenas, revisan los modelos heredados de la vanguardia promoviendo un diálogo fértil entre la experimentación de las formas y la conciencia sociohistórica y cultural en la indagación de aristas trascendentes de la existencia.

Uno de los fenómenos de mayor interés de la segunda mitad de la década del sesenta reside en la diversificación que comienza a registrarse en el género y la aparición de proyectos estéticos que rebasan las necesidades expresivas nacionales.

Biografía de un cimarrón (1966) y Canción de Rachel (1969), del poeta Miguel Barnet, inauguran la llamada novela-testimonio y dotan a la narrativa cubana de un método que eleva eficazmente lo factual a una instancia artística. Apoyado en la etnografía y en la antropología, Barnet reconstruye la vida de individuos pertenecientes a sectores sociales marginados y explotados en la sociedad anterior con el mismo empeño dominante en la novelística cubana de entonces: la recuperación de una identidad alienada durante el período republicano.

La aparición de esta modalidad genérica, que legitima el realismo documental en una nueva dimensión estética, abre posibilidades expresivas para el tratamiento de temáticas sociales que se desean integrar a la conciencia colectiva.

El ciclo iniciado con Biografía de un cimarrón se completa en la década del ochenta con Gallego (1983) y La vida real (1986), obras que corroboran la funcionalidad del método y la pericia narrativa del autor. 
En 1966 se publica también El libro fantástico de Oaj, de Miguel Collazo, primera muestra de la novela de ciencia-ficción en Cuba, antecedente de las manifestaciones de esta modalidad en los años ochenta. Hasta ahora, la novela de ciencia-ficción cubana se detiene en la reflexión ético-social en torno al hombre y su destino, siempre dentro de una expectativa esperanzadora del futuro, como en Espiral (1982), de Agustín de Rojas, lo que le proporciona un rasgo distintivo en el panorama continental. Dos años más tarde es mencionada en el premio de la Unión de Escritores Enigma para un domingo (publicada en 1971), de Ignacio Cárdenas Acuña, indicio del surgimiento de la novela policial, movimiento de amplio desarrollo en las décadas siguientes, y que cobra en El cuarto círculo (1976), de Luis Rogelio Nogueras y Guillermo Rodríguez Rivera, así como en Joy (1977), de Daniel Chavarría, un grado apreciable de facturación literaria.

La década del sesenta, pues, trae a la novelística cubana no sólo un crecimiento cuantitativo y la aparición de modalidades genéricas antes inexistentes, sino también un campo ideotemático que provoca la exploración desde diversos ángulos. El re-conocimiento del paisaje y el hombre, la modelación literaria del perfil psicosocial y cultural cubanos a través de la historia, se imbrica sustancialmente con la conciencia de identidad adquiridas y se correlaciona con el proyecto de transformación de la sociedad. Sin embargo, no será hasta los años setenta que surjan obras que conciban su mundo tomando en cuenta las peculiaridades y contradicciones de la realización práctica del mismo. Sintomáticamente, hasta la fecha ninguna de las novelas en que cristaliza y se regenera el lenguaje vanguardista estructura su plano argumental teniendo como fuente la circunstancia inmediata; todas ellas reconstruyen, desde la perspectiva que da el tiempo y el cambio social, un universo ya periclitado. Cuando se pretende incorporar facetas del presente, el discurso altera su registro y se produce una disonancia; si no lo hiciera, evidencia su impostura.

En los últimos años se ha transparentado nítidamente la necesidad de un lenguaje capaz de modelar con eficacia las provocaciones del área temática emergente después del triunfo revolucionario. La década del setenta inaugura una fase «acumulativa» de pulsaciones en la conformación de ese discurso. Sacchario (1970), de Miguel Cossío, y La última mujer y el próximo combate (1971), de Manuel Cofiño, inician las propuestas centradas en el abordaje de problemáticas inherentes a la construcción del socialismo, el enfrentamiento de valores entre la vieja y la nueva sociedad y la defensa de sus conquistas.

La primera novela de Cofiño, la de más amplia repercusión nacional e internacional, se apropia críticamente de la tradición literaria, se vale de 
los recursos que aporta el método de lo «real maravilloso» para la conformación de un mundo novelesco que centra su significación en los conflictos que genera la supervivencia de conductas y actitudes que provienen de la sociedad prerrevolucionaria y aquéllos, ya vigentes, promovidos por la revolución. En este sentido, La última mujer... posee un valor evolutivo gnoseológico particular dentro de lo que se ha denominado como «novela de la revolución cubana». A diferencia de obras anteriores, el enfrentamiento entre «lo viejo»y «lo nuevo» no se traduce en la crisis de un personaje en tensión entre los dos mundos, inmerso, por tanto, en una trágica problemática existencial; el objetivo principal del novelista radica en escrutar los fundamentos socioeconómicos que sirven de fuente para la contraposición ideológica y ética. El protagonista de la novela, Bruno, encarna el tipo de hombre que ha sido modelado por las nuevas circunstancias sociales. Un nuevo personaje, aun esquemático, un tanto abstracto, pero necesario, ha aparecido en la novelística cubana.

Por otra parte, entre 1974 y 1979 , Alejo Carpentier publica sus últimas novelas: El recurso del método (1974), Concierto barroco (1974), La consagración de la primavera (1978) y El arpa y la sombra 1979), y culmina así una trayectoria y una vocación iniciadas en el fermento vanguardista. Dueño absoluto de un lenguaje y de un ámbito narrativos que alcanza su plenitud en El Siglo de las Luces, en estas obras finales, sobre todo en La consagración de la primavera, se producen aperturas rejuvenecedoras que la muerte detuvo. El «cumplimiento de un destino» - como en el caso de Lezama: Oppiano Licario (1977) - accionará sobre novelistas más jóvenes enriqueciendo sus propuestas.

Por otra parte, escritores que comenzaron a publicar sus primeras obras en la década del sesenta, consolidan su instrumental expresivo, abren nuevas vías de indagación y revelan un nivel apreciable de madurez dentro del género. Ejemplos elocuentes son El pan dormido (1975), de Soler Puig, y Temporadas de ángeles (1983), de Lisandro Otero.

La cuarta novela del autor de Bertillón 166 representa uno de los mayores logros de la literatura cubana en la década del setenta. La funcional utilización de una estrategia discursiva amparada en la experiencia de la novelística latinoamericana contemporánea, el aporte de un punto de vista narrativo inédito, así como la noble visión que ofrece de la sociedad de Santiago de Cuba en los años treinta, muestran la madurez literaria alcanzada por Soler Puig. Por su parte, Temporada de ángeles señala la plenitud expresiva de Otero, quien estableció un hito con La situación veinte años antes. Novela histórica, barroca como la época que reconstruye, la revolución inglesa del siglo XVII, aúna documento y ficción para hacer reflexionar al lector, desde su presente, sobre la manera en que el hombre ha encarado 
sus tareas en medio de utopías y alucinaciones. Por esta vía, la obra de Otero guarda nexos con las propuestas de Alejo Carpentier; de hecho, resulta un homenaje y, a la vez, el replanteo de concepciones y formas artísticas que garantizan la continuidad y la renovación.

Otros novelistas exploran temáticas de interés o abren nuevas vías al desarrollo de la tradición: Gustavo Eguren, con Aventuras de Gaspar Pérez de Muela Quieta (1982), reactualiza la novela picaresca, experiencia que luego continúa Luis Felipe Bernaza en Buscavidas (1985); el poeta y ensayista Cintio Vitier, uno de los integrantes más valiosos de Orígenes, publica De Peña Pobre (1979), Los papeles de Jacinto Finalé (1984) y Rajando la leña está (1986), concebidas como partes orgánicas de un mismo proyecto narrativo; Antón Arrufat, poeta y dramaturgo, en La caja está cerrada, ofrece una imagen de las pequeñas miserias y esperanzas cotidianas del Santiago de Cuba de los años cuarenta, un mundo que incuba las motivaciones vivenciales que calladamente conducen a la revolución. Reynaldo González, por su parte, propone un nuevo modelo estructural polifónico para la novela-testimonio con La fiesta de los tiburones (1978), multifacética reconstrucción de una etapa de la vida republicana. En 1977, la publicación de El comandante Veneno, de Manuel Pereira, indica el arribo de una nueva generación de novelistas que apenas salían de la niñez en 1959. Su rasgo más notorio, por el momento, reside en una óptica despojada del «exorcismo» apuntado por José Rodríguez Feo como característica de las promociones anteriores; sus obras no rezuman las consecuencias de una crisis existencial ni la asunción explícita de una voluntad política, sino la manera orgánica en que se ofrece un diagnóstico de las circunstancias sociales y su repercusión en el hombre. Desde el punto de vista artístico, esta generación muestra una notoria preocupación por los modos expresivos legados por los maestros de la narrativa contemporánea, particularmente por Alejo Carpentier y Gabriel García Márquez; de ahí que, como es presumible en obras primeras, en los textos publicados a ratos se siente más el ejercicio estilístico que la elaboración de un discurso significativo, acorde con las vivencias propias. No obstante, novelas como la señalada de Pereira, El candidato (1979), de Alfredo Antonio Fernández; La habitación terrestre (1982), de Miguel Mejides; La hora de los mameyes (1983), de Mirta Yánez; Un rey en el jardín (1983), de Senel Paz; Balada del barrio (1984), de Bernardo Marques Ravelo; Los términos de la tierra (1985), de Alejandro Querejeta, y El cumpleaños del fuego (1986), de Francisco López Sacha, conforman un conjunto narrativo de interés tanto por su espectro temático como por su nivel en el manejo del lenguje.

La novelística cubana en las décadas del setenta y ochenta muestra tal diversidad de proyecciones, que permite vislumbrar una nueva etapa de 
cristalizaciones no muy lejana. La vocación social y la humana, unidas a la reactivación de las formas, constituyen la base de ese proceso. Por esta vía, el discurso novelesco comienza a reclamar su propio espacio en el mundo de la cultura y de la sociedad en general, desde el cual puede incidir activamente, críticamente, en la conciencia del lector y en su realidad. Esta es la mayor apertura que promueve Las iniciales de la tierra (1987), de Jesús Díaz, novela polémica, aun en sus relaciones intertextuales con una zona de la narrativa anterior, que preludia el cambio del signo estético por venir.

Si el tratamiento del presente revolucionario en las primeras novelas de la década del setenta, y en particular en la obra de Cofiño López, enfatizaba en las condicionantes contextuales que fraguaban las conductas éticas y políticas y tendía al diseño de un héroe «típico», en Las iniciales de la tierra se recupera sustantivamente la característica antropocéntrica del género y se debate la trayectoria existencial, las caídas y resurrecciones de un hombre cuya vida está íntimamente vinculada al quehacer revolucionario. Experiencia de una generación, mirada interna a la historia, recreación de estratos socioculturales y lingüísticos de una realidad compleja, tamizada por las entretelas psíquicas del personaje, sus apetencias y limitaciones, conforman un mundo novelesco pluridimensional capaz de movilizar la conciencia del lector y ofrecerle una lectura desautomatizada de su entorno, una revisión de sí mismo, avalada por un alto nivel de realización artística. En esta primera novela de Jesús Díaz pudieran estar las señas del futuro.

Esta ha sido la trayectoria de la novela cubana contemporánea hasta hoy; éstos son los deslindes y alternativas propuestos. Mientras tanto, los propios escritores afrontan sus desafíos, aquéllos que luego serán los nuestros.

Octubre de 1987. 